\title{
Effect of Re-Entry Policy Implementation on Readmitted Girls' Academic Performance in Mathematics in Selected Secondary Schools of Mufulira District in Zambia
}

\author{
Nsalamba Gladys ${ }^{1}$, Simpande Alex ${ }^{2}$ \\ ${ }^{1}$ School of Mathematics and Natural Sciences, Copperbelt University, Kitwe, Zambia \\ ${ }^{2}$ School of Education, Copperbelt University, Kitwe, Zambia
}

Email address:

gladysnsalamba@gmail.com (N. Gladys)

To cite this article:

Nsalamba Gladys, Simpande Alex. Effect of Re-Entry Policy Implementation on Readmitted Girls' Academic Performance in Mathematics in Selected Secondary Schools of Mufulira District in Zambia. International Journal of Data Science and Analysis.

Vol. 5, No. 5, 2019, pp. 73-85. doi: 10.11648/j.ijdsa.20190505.11

Received: July 13, 2019; Accepted: August 22, 2019; Published: October 5, 2019

\begin{abstract}
Zambia is one of the countries in the Sub-Sahara Africa that has an established Re-Entry Policy. The policy was declared in 1997 and allows pregnant school girls to go to school. The aim is to create academically healthy learning institutions in which both girls and boys are free. As per findings of this research, the Re-Entry Policy has helped reduce gender discrepancies in terms of equity in education. Sad though, the paper has reviewed that most reentered girls fail mathematics, a thing that disadvantages them because mathematics is used as criteria of purity for admission into university and well-paid jobs. As such, the purpose of this study was to investigate the effect of Re-Entry Policy implementation on readmitted girl's performance in mathematics. In order to achieve this aim, a qualitative research approach guided by some research questions and objectives was undertaken. Data relating to the research was collected through interview guides and questionnaires, and analyzed using narrative techniques. Furthermore, purposive sampling technique was used because the study targeted a specific group of people and characteristics. The conclusion made through the findings of this paper were that the perceived poor performance in mathematics by reentered girls is a 'socio construct' and not solely due to the Re-Entry Policy. This implies that the implementation of the policy is what is key; hence, the variations in performance for reentered girls in individual schools.
\end{abstract}

Keywords: Gender, Gender Stereotyping, Gender Roles, Re-Entry Policy, Performance, Reentered Girls, Sex

\section{Introduction}

Before the declaration of the Re-Entry Policy by the Ministry of Education, any girl who became pregnant was expelled from school. Two hundred and fifty thousand girls aged between seven and thirteen years dropped out of school due to pregnancy related expulsions.

The practice of expelling girls who became pregnant from school attracted the attention of social actors and activists

across the Globe. Coupled with the campaign for Affirmative Action, started by the American president, John F. Kennedy, the world was on a crusade to end stereotypical elements against girl child education [1]. It was through this campaign that the Re-Entry Policy came to fruition. The other observation made by the world community of nations was that the harsh laws that led to a number of pregnant school girls being expelled, did not act as a deterrent to would be victims. Instead, teenage pregnancy kept on escalating. Round table discussions and conferences were held by world leaders with intent to finding lasting solutions to teenage pregnancy and the status of girl child's education.

Time had come to remove impediments to Girl Child Education such as the continued practice of expelling pregnant school girls. This came about due to a realization that teen pregnancy was a social problem, and continued to rise despite expulsions thereby widening the gender gap with females being the most marginalized in the academia world as well as employment.

By the 1990s, the situation had become so desperate in Zambia. Worse still, it was now considered a norm to have 
pregnant school girls expelled from school. The spread of Affirmative Action however, opened another era characterized by a call for 'Women Emancipation'. The Civil Society, Social Actors and Government Activists championed it. They mounted undue pressure on Government to repeal the Education Policies that discriminated the girl child.

The Re-Introduction of Multi-Partyism in 1991 coincided with the wind of change as far as the perception of rigid educational rules such as expulsion of pregnant school girls was concerned. The 1977 Educational Reforms found no common ground with the Liberal Educational System. For this apparent reason, the 1992 Focus on Learning replaced it and later, the 1996 Educating Our Future, whose focus is equity and equality. These were inclusive policies that aimed at the creation of less-restrictive learning environment for all children regardless of race, creed, religion or physical conditions, which included pregnancy.

Arguments advanced by the international community and social activists against expelling pregnant school girls was that, it is not a crime to be pregnant and teenage pregnancy was a growing social problem requiring a multidisciplinary approach with competing solutions [2].

Expulsion of pregnant school girls was equated to a death sentence for a crime never committed. Like any other social problem (for example, HIV/AIDS, Hunger and Human Trafficking), Teen pregnancy has identifiable causes and a tendency of endurance over time.

Influenced by cultural lag, some communities, especially those in peripheral (rural areas) have not taken advantage of the amnesty given to teen mothers by the Re-Entry Policy. The 'drop out' prevalence due to teen pregnancy in these areas is still very high. Inculcated by the harsh laws of the First and Second Republic, they do not appreciate the fact that a girl child who has become pregnant can continue with her education and do better in all subjects, including mathematics.

Teen mothers exhibit feelings of self-unworthiness and pity. They seem not to see the value in schooling anymore. For example, a research carried out in Kalomo, early in 2003 reviewed that delivering parents did not see the practicability of the Re-Entry policy because teachers and policy makers did not help their parents understand the importance of returning to school.

The expulsion of pregnant girls has greatly contributed to women underdevelopment. It has helped maintain the status quo with females being the most marginalized members of society and explains the reason why men have been dominant in the country's economic and political space since the dawn of independence to date. Even the most pronounced First Cabinet of the liberal Government in 1991 led by Dr Fredrick Chiluba was male dominated. The trends have continued in present day Zambia not because of expulsions of pregnant school girls but the quality of results by the reentered in mathematics.

In June 1995, the Zambia Association of University Women organized a conference on the status of a girl child to drive the need for equity and equality in education. It was at this conference that the call for the Re-Entry Policy gained strength.

While applauding the efforts made by pioneers of ReEntry policy, the general perception is that its implementation is far below the expectations of society. Furthermore, the academic performance of girls reentered in school after maternity leave has not been impressive with the worst being in mathematics. The study therefore sought to investigate the effect of Re-Entry Policy implementation on the performance of readmitted girls in mathematics. It is believed that, poor grades in the subject make it difficult for them to break the vicious cycle. It also analyses the effectiveness of the measures put in place by individual secondary schools under study in meeting the goals of the Re-Entry Policy.

\section{Methodology}

The study was guided by a qualitative research design. Qualitative research design is interpretive and ethnographic in nature [3]. It makes use of subjective methods in assessing opinions, behavior and attitudes [4]. A Qualitative approach mostly take the form of induction, meaning it involves building a theory on the information and data collected [5]. Choice of design was influenced by the fact that the study concerned itself underlying reasons, opinions and motivations of the subject matter, thereby, providing insight into the problem and generate new ideas. Considering the nature of the study, participants were purposively selected and the sample comprised of twelve teachers, twelve parents, two officers from the District Education Board Office and thirty-four reentered girls giving a total of sixty people. The qualitative data collected was analysed by narrative techniques.

\section{The Global, African and Zambian Positions on the Re-entry Policy}

\subsection{The Launch of Re-Entry Policy in the World Community, Sub-saharan Region and Zambia}

Bothered by the widening gender gap with women being the most marginalized in education and the world of work, the world community of nations set goals for itself to achieve by the dawn of the $21^{\text {st }}$ Century. This forced world leaders to come up with educational policies whose core was the future of the plight of the girl child. A conference on Education for All was therefore held in Jomtien, the Capital City of Thailand in 1990. It was here that the year 2000 was set as a target for countries to achieve Universal Basic Education for All and Equity in Education. As the magical year drew nearer, Governments in the Sub-Saharan Region and the world at large devised measures aimed at removing discriminatory clauses in their educational policies such as the expulsion of pregnant school girls in a quest to bring about gender equity, hence, the launch of the 'Re- Entry Policy.' The Dakar Conference held in the year 2000, challenged the world community of nations to ensure gender 
equity is attained through the adoption of strategies to promote girls' education [6].

However, it should be noted that only three countries in Sub-Saharan Africa have well established Re-Entry Policies namely; Botswana, Kenya and Zambia. The rest of the countries have the policy still in its draft form.

Botswana was the first country in the region to have a crystal-clear policy allowing pregnant school girls continue with their education after delivery, dabbed 'Republic of Botswana Education Regulations (1978). Other countries also followed suit by coming up with their Re-Entry policies. These were; Ministry of Education and Vocation Training, 1993 (Malawi), Re-Entry Policy, 1997 (Zambia) and Return to School Policy Guidelines, 1998 (Kenya). Tanzania is still skeptical and the policy though in its draft form remains unclear when it will be approved. Furthermore, there are also variations in the content and application of the policies by individual countries, notably on practices, mandatory pregnancy screening, and amount of leave before Re-Entry and allowance of pregnant girls in school. Whether established or not, the fact is that all countries in the region implement the Re-Entry Policy.

The Re-Entry Policy aimed at implementing measures preventing the exclusion of teenage mothers from achieving their educational dreams. The Zambian Government observed that unequal socio-cultural constructs coupled with Pre-1997 rigid educational policies led to an increase in girls dropping out of school. Time was ripe when the plight of teen mothers needed consideration by the Government and other stakeholders.

The year 1997 will therefore remain a landmark in Zambian history for the beginning of a new era in the life of a girl child. Amnesty was given to the girl child after so many years of affirmative action calling for gender equality and equity. Social actors in Zambia triumphed and scored great success in this regard making Zambia to join the rest of the world in championing girl friendly policies like the ReEntry Policy. The future for the girl child was now certain and full of hope for a better lifestyle. As such, teen pregnancy was no longer a red tape for inclusion in the mainstream education system

It is absurd to reprimand pregnant school girls and use their fate as an excuse to deter them from continuing schooling. Sending them away from school at a tender age was the worst and injustice act. However, the effectiveness of the Re-entry policy is shouldered on uncertainties in terms of the role the stakeholders needed to play in the implementation of the Re-entry Policy.

\subsection{Prevalence of Adolescent Pregnancy in the United States of America}

Adolescent pregnancy is a universal social problem caused by a number of factors. The study conducted by Testa in the United States of America on "Teenage Parenting: Challenges and Issues", confirmed that teenagers, especially in the ages of ten to fifteen were the quickest growing population of parents [7]. Another survey by the Centre for the Study of Adolescents (CSA) conducted among secondary school students revealed that 3 in 10 adolescents begin child bearing by the age of eighteen [8]. The CSA research has further indicated that teenagers account for $30 \%$ of non-marital births in America, a situation not very different from the Zambian situation. In fact, teenage pregnancy is one of the main barriers to the educational achievement of girls in many developing countries of Sub-Saharan Africa [9].

\subsection{Prevalence of Adolescent Pregnancy in Zambia}

Data drawn from the 2013-14 Zambia Demographic and Health Survey (ZDHS) and the 2010 Census of Population and Housing confirmed that the prevalence of adolescent pregnancy is high [10]. Similar to the studies carried out elsewhere as was the case with the United States of America, teenage mothers in Zambia are equally among the fastest growing population. In 2013, statistics showed that $28.5 \%$ of girls aged fifteen to nineteen had been pregnant either before or given a live birth.

The incidence of pregnancy among teenagers was identified as a serious growing problem in the world, especially in the poorer nations [11]. However, the prevalence rate varies according to provinces and districts. Urban provinces and districts have the lowest percentage.

For example, Copperbelt has the lowest portion of girls aged 15-19 becoming pregnant in Zambia because it is predominantly urban. Western Province is the highest and stood at $38-41 \%$. Another province with the highest pregnancy prevalence is North-Western Province (41\%).

In towns and cities, pregnancy prevalence for teenage pregnancy is high in suburbs, unplanned settlements and generally poor communities making about 45\% [12]. Cases of pregnancies are higher in rural secondary schools and those located in the low wealth quintile areas of towns and cities.

Furthermore, the research conducted by the Copperbelt Educational Team in all districts on the Copperbelt Province of Zambia indicated that in the 2017 Annual School Census, 1,232 girls fell pregnant, out of which only 657 (53.33\%) were re-entered in school. This simply shows that teenage pregnancy is a social problem

The report given in April, 2018 by the then Gender Minister, Honorable Victoria Kalima (Late) on the launch of the National Plan on Ending Child Marriage 2016-2021 at Redison Blue Motel in Lusaka disclosed that teenage pregnancy statistics stood at $29 \%$, Child marriage rate at $31 \%$ while HIV prevalence for Girls was at $8 \%$. The expectation was that the prevalence rate for teenage pregnancies and child marriages 21 years after the launch of the Re-Entry Policy coupled with other interventions like comprehensive sexuality education would be very low, possibly at zero.

\subsection{Determinants of Adolescent Pregnancy in Zambia}

Factors associated with adolescent pregnancy are complex and often intertwined and driven by various social, economic, and sexual-relation patterns that are further influenced by other underlying issues such as age, peer-group experiences, 
gender dynamics, and vulnerabilities created by various circumstances in which adolescents find themselves [13]. Overall determinants of adolescent pregnancy from the study were classified into five categories as:

i. lack of access to appropriate sexual and reproductive health information and services, particularly contraceptives;

ii. poverty, making some girls to offer sex in exchange for money, goods, and services;

iii. social and cultural determinants, such as gender inequality (women and girls perceived as the weaker sex), child marriage, and peer pressure;

iv. lack of information and education on sex and sexuality; and

v. Lack of opportunities for adolescents, particularly for those living in rural areas, such as school boarding facilities and social services such as long distances to schools, health facilities, and entertainment.

\subsection{Consequences of Teenage Pregnancies on Girl Child Education}

Before the launch of the Re-Entry Policy, the ultimate punishment that was given to girls who became pregnant was expulsion. This act led to untold suffering for girls. It was this and many other rigid educational policies that led to more than $40 \%$ of girls in developing countries being married off before their 18th birthday [14]. However, these laws did not stop girls from becoming pregnant because the act itself is a social problem, which should be solved through social means, that is, application of sociological theories and principles.

The problem has attracted different interest groups. Different campaign messages such as "Girls not brides" and "Save the Girl Child" have been launched by various organizations. As a result, the numbers of pregnancy cases have steadily decreased over the years.

Evidence from core and peripheral states show that teenage pregnancy is a precursor for abject poverty both as young and later old women of society [15]. Further research revealed that teenage mothers were often themselves born to teenage parents and were likely to end up both as single parents and bring their children up in poverty [16]. This led to flagging off the campaign for Re-Entry Policy by the Civil Society and Social Entrepreneurs. It was later adopted by world governments, Zambia in particular.

The expulsion of girls who became pregnant was a double punishment for them. First was the shame and humiliation that came with parenting at a tender age. Secondly, the boys and men who impregnated them were in most cases irresponsible, leaving them to shoulder the burden of raising the child alone. The only way to survive was marriage. For some, the solution was to continue having children from different men in a bid to get rid of the first mess.

The Re-Entry Policy became a window of hope for teenage mothers. However, as noted in some countries, the policy has brought more harm than good in as far as quality education is concerned. In Tanzania, President Magufuli publicly denounced the Re-Entry Policy on $23^{\text {rd }}$ June 2017.
He warned school girls against teenage pregnancy and these were his words "after getting pregnant, you are done': No more school for Tanzanian mums-to-be" His sentiments received mixed reactions and condemnation from Governments and civil rights movements in support of female education and Sustainable Development Goal (SDG) number five (5). Among other things, this justified how thorny the policy is in so far as moral and quality assurance in education is concerned across the globe, especially when associated to their performance in mathematics.

While the MoE's motive in coming up with Re-Entry policy was to eliminate gender imbalances in the provision of education, a good number of girls are actually abusing the policy by becoming pregnant several times after reentry into school.

\subsection{Stigmatization of Teen Mothers Readmitted in School and How It Affects Their Performance in Mathematics}

Stigma is a disgrace and a sign of rejection by society. It is a shame attached to something regarded as socially unacceptable [17]. Stigma against teen mothers is so real. They are regarded as morally tainted and often placed in separate classes and sitting arrangements lest they contaminate others with teen sexuality. Though sensitizations have taken a center stage for two decades now since the launch of the policy in Zambia, the hostile socio-cultural environment at home and school is a leading cause for teenage mothers dropping out of school. More than two thirds of teen mothers do not finish their education [18].

The hostile social-cultural contexts in which they find themselves affect their academic performance with the worst being in mathematics. The communities in which teen mothers come from has a greater impact on their schooling. Instead of encouraging them, they are treated as 'other girls' with low or no morals. Much of their time is spent on self-pit and condemning themselves for getting involved in acts which led to the pregnancy at the expense of academic work. They are loners and the majority of their initial friends now look to them as mothers.

Parents of their former friends no longer allow them to come anywhere near their homes on grounds that they are a bad seed. Cooperative approaches to teaching and learning do not work well for them due to stigmatization and labels tagged to them by their friends, the community and at times teachers. Some of the girls who returned to school after delivery found it difficult to interact with fellow learners partly because of their conscience and their changed physical shapes. They tend to withdraw, hence, affecting their performance in mathematics.

The only source of knowledge for teenage mothers is the teacher and not fellow pupils. They are restricted to self and become timid. This feeling of rejection and belonging to the out-group cause emotional and cognitive dissonance. The result is poor performance in mathematics. To the slow learners and academically challenged, the situation is worse.

Back home, the teen mothers are subjected to unwarranted pressure and induced stress by their parents and peers. Before 
going on maternity leave, the pressure however is relatively low but expands afterwards. The fact that man is a social being, these attributes will definitely have adverse effects on concentration levels and subsequently cause poor performance in mathematics. Moreover, Psychologists argue that social interaction is cardinal in a learning process [19]. A teen mother denied positive social interaction in the manner explained above therefore has few chances of performing well academically. This act of social pathology exerted on teen mothers even make them hate the school environment and the entire learning process.

A study conducted in United Kingdom (UK) on how stigmatization negatively affect teen mothers' performance in mathematics found out that 'stigma' was related to how they will cope with anonymity accompanied by attending school [20]. However, the experiences of teen mothers in individual schools are different. The implication here is that what matters is how the Re-Entry Policy is being implemented. Instances where there were separate schools for teenage mothers, it was found that mothering girls performed better in their academic work, concentration was high and completion rates were equally high.

Based on this, the poor performance in mathematics by teenage mothers is therefore a social construct caused by stigma.

\subsection{Lack of Social Support to Teenage Mothers and Its Effect on Their Performance in Mathematics}

Despite the United Nations Children's Fund and most women's Non-Governmental Organisations being in full support of the Re-Entry Policy, the church, the Zambia Union of Teachers, some parents, teachers and pupils opposed the move. This is evident from the findings of the study by Zambia Association for Research and Development (ZARD) between October and December 1997 when it carried out an opinion poll on the readmission of pregnant girls to school after giving birth. According to the findings of the study, the church, parents, teachers and pupils were against the declaration fearing that it will promote immorality.

Poor performance in mathematics and other subjects by teen mothers is also attributed to inadequate home schooling and special programs like counseling [21]. They are seen to be immoral and unprincipled as well as a disgrace to the family, worse still, adults who should fend for themselves. They have a duty of raising their baby while at the same time concentrating on academic work amid negative sentiments from parents at home.

Since mathematics require a sober mind, the disturbance by the child and parents coupled with a feeling of rejection definitely makes it practically impossible for them to get good grades. They can hardly write their home works. Instead of offering words of encouragements and counseling to cushion psychologically a despaired mind following the pregnancy, the home environment adds more salt to the wound.

The hostility exhibited by parents, sisters, brothers and relatives at home complicates the chaotic situation surrounding their mess. Teen mothers feel they have nothing left to fight for in life, as theirs is a destiny in doom. Working hard at school more so in mathematics becomes a sheer waste of time. Negative sentiments from those around them in the home because of the baby unconsciously influence their will power and ability in mathematics. Rationalization and other defense mechanisms comfort them as mothers not pupils. This level of acceptance therefore is detrimental, as it becomes an ultimate excuse for their failure in mathematics. They fail to struggle, acclimatize and concentrate in school, Worse still, the poor grade they get in mathematics limits their chances of ever living a better life in future. Furthermore, they are at great risk of being single parents causing them to get involved in unstable relationships that subsequently lead to contraction of sexually transmitted diseases like HIV/AIDS and eventually death leaving the child suffering [22].

Research has shown that many teenage mothers return to school for the sake of their babies and are determined to finish school to take care of them [23]. Nonetheless, the girls' failure to cope with schooling is due to their babies and to the fact that stakeholders in education and parents give up on them and fail to take their plans seriously once the girl had a baby [24]. Teachers also contribute to teen mothers' low achievement by not encouraging them.

\section{Results}

\subsection{Perception on the Re-Entry Policy by Stakeholders}

Headteachers for the selected secondary schools had this to say, "The policy is good and could not have come at a better time than this when society has evolved to value the contribution of women socio-economic growth and development." It was noted that the number of girls dropping out of school in the years preceding the declaration of ReEntry Policy was relatively high. However, today teenage pregnancy is no longer a red tape for girls failing to attain secondary and subsequently university/ college education.

One of the Headteachers bemoaned the poor results of reentered teen mothers in mathematics. In its current form, observed another headteacher, the policy just emphasizes on terms and conditions of the maternity leave awarded to girls.

In her view, most parents do not understand their roles on reentered mothers to help them cope with their newly found status due to unclear guidelines of the policy and the manner school authorities administer it.

Pregnant school girls equally have problems in understanding the policy and do not mind its consequences. All what they know about the policy is that it allows them to stay away from school and then be readmitted after a given period of time. Seeing one of their own being given amnesty in this regard reduces the fear in would be victims of teenage pregnancy. Based on this understanding, one of the Headteachers perceives the policy to be a source of moral decay among school going girls.

However, the conclusion made by one of the head teachers 
on the subject matter was that the policy itself is good, but abused on grounds that olive branch is extended to those who fall prey to the circumstance even when intended for. He equally reaffirmed the concern raised by his colleaque that it is a recipe for moral decay. Moreover, there are no crystalclear guidelines, for example, the point at which one ceases to be eligible for readmission in the mainstream school and the number of times one has to be reentered. If viewed from this perspective, the policy lacks merit in so far as quality results is concerned, especially in subjects that call for optimum attention like mathematics.

Generally, the headteachers perception on the Re-Entry Policy is that it is not helping to improve the performance of reentered girls in mathematics neither has it reduced the discrepancies between boys and girls in mathematics related courses because of poor results by reentered girls.

Head of departments for mathematics in the four selected secondary schools expressed varying views and perception regarding the implementation of the Re-Entry Policy being a cause for reentered teen mothers' poor performance in mathematics.

Two heads of department, from different schools, noted that mathematics is a challenging subject that requires total commitment and enough learning time.

Commenting on the need for maximum commitment and time, the mathematics head of department from another school, wondered how a pupil who has been absent for twothree terms nursing her pregnancy and inconsistent in attendance due to problems that come with child bearing can get a good grade in mathematics. His colleague was quick to mention that mathematical concepts are built from prior or baseline knowledge. Baseline or pre-requisite knowledge on a particular topic or concept is lost thereby breaking the chain.

From the records, one of the heads of department for mathematics discovered that more than $75 \%$ of maternity cases involve learners with low mathematical abilities. She noted with regret that being on maternity leave up to a maximum of six months further dwarfs their already low ability in the subject resulting in poor performance.

All the heads of department for mathematics from the four secondary schools under study claimed that teen mothers are engaged in remedial work as a measure to enhance their academic ability in the subject. However, one of them observed that remedial work for reentered girls is not well administered and monitored by individual schools thereby making it difficult to track their records and performance.

The general perception by these heads of department from the secondary schools under study was that the measures put in place to ensure reentered girls score good grades in mathematics are not strong enough to guarantee improved performance, a thing that justifies ineffective implementation of the policy.

The perceptions of Guidance and Counselling teachers from the four secondary schools regarding the implementation of Re-Entry Policy in relation to reentered girls' poor results in mathematics were similar to that of

\section{Headteachers and Heads of Department.}

In answering the question on the perception of teachers on the implementation of the Re-Entry Policy, the Guidance and Counselling Teacher from one of the schools under study acknowledged that it is met with numerous challenges, one of which was the policy itself. She perceived the policy to cause problems in the sense that, it is not clear on when and how it should be administered. Her counterpart added on to say that the policy has not helped much in creating a less-restrictive and sound academic environment for quality results in mathematics.

Guidance and Counselling Teacher from another school indicated that the policy is good because it allows girls to have a second chance in school after becoming pregnant. She perceives teen pregnancy as a social problem and in that expelling the victims did not change the situation but simply worsened the gender discrepancies, with females being most marginalized.

Despite appreciating the achievements scored by the ReEntry Policy in so far as letting re-entered girls realize their educational goals, one of the Guidance and Counselling Teacher concluded that it is not adding value to the status of women in well-paying jobs and positions because of poor grades in key subjects like mathematics. He further observed that mathematics was the baseline for selection of entry into college, university as well as well-paying jobs. Due to continued poor performance in mathematics, especially by reentered girls, Guidance and Counselling Teachers noted that; "the efforts and resources behind ensuring attainment of equity, equality and quality in mathematics and mathematics related jobs is undermined."

According to them, the main objective of counselling is to create a healthy school environment for reentered girls by helping them adjust amid consequences that come with the status of being a teen mother, and on how to strike a balance between school and responsibilities that come with childcare. They also reiterated the need for parental care and involvement, which is lacking to most teen mothers. Opposed to offering psychological cushion to the reentered girls, parents cause serious emotional torture on them due to castigations and acts of humiliation, a thing that results in lack of concentration and failure in mathematics.

From the Guidance and Counselling desk, it is clear that the perception on the policy is good. The point of departure is the manner it is being administered by individual schools and the poor results for reentered girls in mathematics.

Seven of the twelve parents who participated in the study showed a positive attitude and perception towards the policy while five called for reversion to the pre-1997 rigid education policies. Among other reasons advanced by those supporting the policy were:

i. It has led to a reduction in gender discrepancies between male and females in education.

ii. Educating a woman was synonymous to educating the whole family.

iii. It has reduced rejection of teen mothers in the community and in that; teen pregnancy is no longer a 
curse but a social problem.

iv. Re-entered mothers have become ambassadors of change to other girls and the general female populous.

On the contrary, those opted for the reversal to the pre1997 education policies pointed to an increase in promiscuity that has led to an increase in pregnancies in schools.

When asked about the effect the Re-Entry Policy has on reentered girls' performance in mathematics, most of them cast their blame on schools. They said that the problem is not with the policy but poor implementation by school management and administration, as very little or nothing as has been done to guide re-entered girls on how to utilize the Re-Entry Policy

Another perception given by parents on the relationship between the Re-Entry Policy and performance of reentered girls in mathematics was that there is no way they can pass because of the demands that come with child bearing. The argument was that it is practically impossible for an individual to serve two masters at once. You serve one and despise the other. Some even said that this is a Biblical concept. In their view, instead of forcing the girls go to school, they should be left to move on and eventually get married. The Re-Entry Policy according to them compromises the quality of education and largely a recipe for moral decay. The three PTA Chairpersons perception is that there is too much reluctance on the parents of reentered girls in ensuring they get back on track and get good grades in mathematics. For example, one of the PTA Chairpersons gave an emotional story of two teen mothers who were abandoned by both their parents and men responsible. They find difficulties to go to school at the expense of fending for their babies, renting and meeting other social needs. He noted with regret that given the situation at hand, the duo lacked concentration at schoolwork leading to poor results in mathematics.

Some reentered girls talked to, said that they suffer humiliation and stigmatization from teachers and pupils. As a result, it is very difficult for them to concentrate on academic work, hence, the poor performance in mathematics.

A re-entered girl talked to acknowledged having benefited from the policy. In her view, it gives teen mothers an opportunity to be in school. The only problem however is the mockery they are subjected to. Another teen mother said that she often misses classes due to complications that come with pregnancies. She further indicated that, there are no measures put in place to help teen mothers' catch up with academic work apart from advising them to copy notes. While this works out for information subjects but the situation is somewhat different for mathematics. This being the case, there is no way re-entered girls can have a good grade in mathematics.

\subsection{The Role of Re-entry Policy Implementation in Reducing Gender Discrepancies in Mathematics, and Mathematics Related Studies}

The Re-Entry policy is always among the agenda for NonGovernmental Organizations (NGOs) and the Government.
Many forums at which the plight of a girl child is the Centre of discussion and concern, the role of Re-Entry Policy implementation in reducing gender discrepancies in mathematics, and mathematics related studies is paramount. The question that begs for answers is on how the policy is helping reduce the gender gap in a society that consider a good grade in mathematics as baseline for entry into university, college and the world of work.

The Headteachers stated that the continued poor performance of reentered girls in mathematics is a clear indication of the wider gap in terms of gender discrepancies between males and females in the subject. With mathematics as criteria of purity, high retention rate for teen mothers does not guarantee success in education and world of work. Instead, it calls for concerted efforts from the teen mother herself least she ends up a destitute due to a poor grade in mathematics.

To validate this observations, one of them went on to say that, school certificate results speak volumes when it comes to the idea of equity in well-paying jobs, a thing that defeats the very essence the policy was launched for.

The headteachers shared the same views and agreeable to the fact that the Re-Entry Policy is not doing justice in so far as re-entered girl's performance in mathematics is concerned.

The heads of department answered the question on the role Re-Entry Policy Implementation plays in reducing gender discrepancies in mathematics and mathematics related studies through the presentation of examination analyses for reentered girls shown in table below.

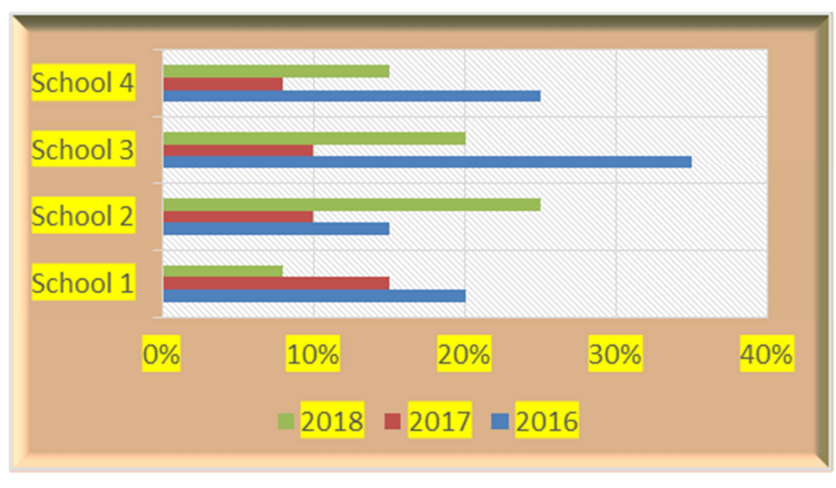

Source: School 1, School 2, School 3 \& School.

Figure 1. Performance of Reentered Girls in Mathematics for the four selected secondary schools at grade 12 in the period 2016 to 2018.

The role the Re-Entry Policy plays in reducing Gender Discrepancies as seen from the examination analyses presented by Heads of Department for Mathematics of individual secondary schools under study is worrying. The head of department from school 1 said that the Re-Entry Policy is a shame and a failure because of the poor performance by reentered girls in mathematics. This means that the gender gap between males and females will remain the same, with females at the lowest class. According to the head of department from school 2, the performance of girls in mathematics is skewed towards the fail.

The head of mathematics department at school 3 proposed the 
abolishment of the Re-Entry Policy because re-entered girls do not perform well in mathematics and other disciplines too. Referring to the past 2016, 2017 and 2018 examination analyses for his school, the implementation of the policy has not helped change societal perception that nothing good can come out of teen mothers in as far as reducing the gender gap is concerned. He went on to say that gender discrepancies can only be reduced following the introduction of rigid rules such as the ones that existed before 1997.

"The presence of teen mothers in school compromise moral standards thereby contaminating the rest of the girls with teen pregnancy and bad behaviors detrimental to sound academic performance. This being the case, they lack concentration resulting into poor performance in mathematics. A poor grade in mathematics definitely reduces the chances of girls getting better jobs and ascendance to influential decision-making positions. Therefore, a good grade in mathematics is a necessity in the present day, meaning that girls are marginalized because of poor results in the discipline. This explains the reason why males have remained dominant in mathematics and mathematics related courses" said the head of department for mathematics in school 2.

Eight out of twelve parents talked to wondered how reentered teen mothers could be equal to the task or be at the same level with their colleagues who remain in class throughout the period they are on maternity leave. They pointed out that such pupils deserved to fail the examinations and this includes mathematics.

In reality, they saw the failing in mathematics by reentered girls as something that dragged them in the mud such that it becomes difficult for them to join well-paying and prestigious jobs. In line with this thought, the general view by parents is that the Re-Entry Policy has just helped increase access to education and unconcerned of quality results in key subjects like mathematics. It is in this view that they remain indebted to believing it does not reduce the gender discrepancies in mathematics and mathematics related courses or employment

\subsection{Challenges Faced by Reentered Girls and How They Affect Their Performance in Mathematics}

The main challenges faced by reentered girls that subsequently leads to poor performance in mathematics cited by participants are stigma, lack of parental support, low selfesteem and role conflict.

Table 1. Causes of poor performance for reentered teen mothers in mathematics Source: field Data.

\begin{tabular}{lll}
\hline RESPONSES & FREQUENCY & PERCENTAGE \\
\hline Low Self esteem & 8 & 20 \\
Lack of Parental Support & 12 & 30 \\
Stigma & 15 & 38 \\
Role Conflict & 4 & 12 \\
Total & 39 & 100 \\
\hline
\end{tabular}

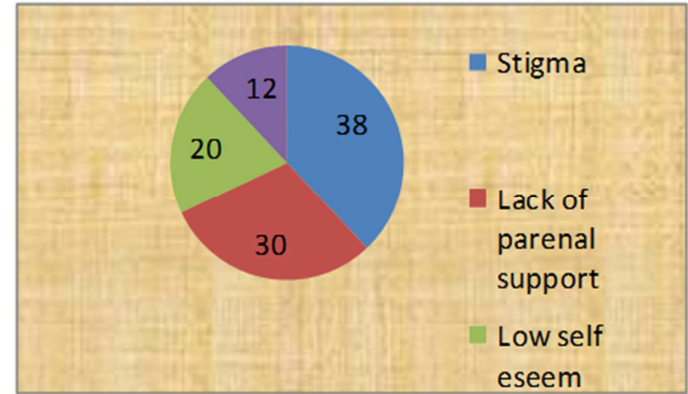

Source: field Data.

Figure 2. Causes of poor performance for reentered teen mothers in mathematics.

Stigma accounted for $38 \%$ of the challenges faced by reentered girls in mainstream school causing poor performance in mathematics.

Most teen mothers interviewed said that they do not feel to be part of the school community and society due to stigma. The feeling of rejection in them is real. For example, four girls who explained how stigma affects their academic performance in mathematics echoed that their experiences have been nasty in this regard. According to them, they are associated to outcasts or people with immoral behaviors, indifferent and condemned. One of them recalled how a mother to a friend openly rebuked her daughter to stay away from reentered girls in school to avoid being contaminated with teen pregnancy.

The Guidance and Counselling Teachers for schools 1 and 3 respectively, also shared similar stories to that of the four girls. They said that these are common cases, which they contend with on a daily basis. Their observation was that such experiences have adverse effects on reentered girls' coping behaviors and performance in mathematics. Commenting on the same, School 1 headteacher said that a number of pregnant school girls are dropping out due to stigma. It should also be borne in mind that the prevalence rate in this regard are high in third class communities, or areas with low levels of enlightenment.

According to the headteacher for School 3, "emotional torture (stigma) exerted on reentered girls by the school authorities, teachers and peers negatively affect their performance in all subjects, with the worst being mathematics." In affirmation, some of the reentered girls said that stigma is too pervasive and makes them feel out of place. They further made an explanation on how it leads to low concentration levels at schoolwork. "Instead of doing school work, for example, solving mathematics, much of the time is spent on nurturing the emotional torture that comes due to a strong feeling of rejection caused by stigma". In other words, the stigmatized re-entered girls are never in their normal psychological framework to accommodate the instructionallearning process. This collates to poor performance in mathematics.

The findings rated lack of parental support to be the second most serious challenge re-entered girls experience in schools and subsequently lead to poor grades in mathematics. 
It stood at $30 \%$

The teen mothers bemoaned lacking emotional, social and psychological support from their parents. This thought was common to all respondents.

However, the observation made was that there are very few parents who ensure their girl children are given the necessary psychological, emotional and social support during pregnancy and thereafter. Their rewards as explained by a reentered teen mother are castigations and humiliations. The head of department at school 2, further said that, it is practically impossible and absurd for teen mothers subjected to such mental torture to get good grades in mathematics.

The Guidance and Counselling Teacher at school 4 had a different view on teen mothers coming from caring and supportive families. According to her, teen mothers coming from homes where parents are understanding and create a warm less-restrictive environment for them exhibited good performance in mathematics.

A caring and supportive parent whose daughter became pregnant in grade ten had this to say; "When I discovered my daughter was pregnant, I quickly accepted and ensured she received care and love like any other child in the house. I treated her as a child and not an adult. My decision and level of acceptance were condemned by most people, including my wife but thank God the girl realized her mistake, soldiered on and eventually got a merit in mathematics and an overall ten points" This success story is an indicator that parent's social, psychological and emotional support are key to improving performance for teen mothers in mathematics.

One of the teen mothers had this to say; "When I look at my friends happily going to school without any tag of being a teen mother, I really feel bad and I wish this unkind land would eat me. At fifteen, I can no longer freely interact with my old friends because their parents think I will contaminate them with teen pregnancy. It all started with this old man who used to come every day at our school driving a big white posh car. How I used to show off to the big boys, who though school mates, seemed to be toys to me. Now all what I used to enjoy is water under the bridge. This old man is married and no longer interested in me. Now a day hardly goes without being mocked by my schoolmates whom I considered toys. Therefore, I am not free in this school and always wish the earth could open up and swallow me just to hide me from this shame."

The head of department at school 3 noted that mockery is a recipe for low self-esteem for teen mothers. They feel like all hope is lost for them and there is nothing they can do to turn the tables around. Coupled with cognitive dissonance, a psychological state when there is a discrepancy between what one feels in the inside and on the outside, low self-esteem observed some respondents reduces teen mothers' abilities to perform well in mathematics. From the data collected, low self-esteem for teen mothers account for $20 \%$ of the causes for their poor performance in mathematics.

Despite the amnesty given to teen mothers through the ReEntry policy to continue schooling after delivery, it was noted that role conflict between schoolwork and child rearing cause poor performance in their academic work. All the girls that took part in this research confirmed this assertion as being true. According to them, it is always a hard experience to be a mother and a pupil at the same time. One of the parents noted that many teen mothers were happy that, they were given a chance to go back to school though their performance was relatively below average due to their dual role of attending school as well as caring for their babies, in cases where they did not have reliable caregivers for their babies.

Since both roles require time and concentration the girls said, one automatically falls out of favor and this is usually schoolwork. In a comment, a teen mother categorically stated how role conflict affected her studies and concentration on schoolwork, especially in mathematics. They wondered how one could have a good grade in mathematics, which by nature is difficult and requires optimum concentration of the highest degree.

In all the four secondary schools under study, the performance of reentered teen mothers in mathematics declined over time due to taking care of their children. In his view, the Guidance and Counselling Teacher for school 3 noted that truancy also contribute to poor performance in mathematics.

Teen mothers are often out of school for as long as their children were unwell, observed the Head of Department for Mathematics from school 2. Meanwhile, their colleagues remain in class and are consistent. Based on this assertion, the head of department for mathematics from school 1 wondered what miracles can be performed to have the reentered girls score good grades in mathematics, a subject that is perceived by many to be difficult.

\section{Discussion and Analysis of the Findings}

\subsection{Perception on the Re-Entry Policy by Stakeholders}

The Re-Entry Policy is generally perceived to be a good policy and in line with "Educating Our Future, 1996", a National Policy on Education whose focus is on 'Equity and equality'. It is in this regard that the Re-Entry Policy found commonplace in the Zambian education system. The policy is in tandem with other educational pronouncements such as the "Universal Basic Education Policy", keeping the girl child in school, comprehensive sexuality education among others.

To this effect as per findings of this research as well as the literature review, the completion rate for girls at secondary school level has increased greatly over the years in the SubSahara Africa, Zambia in particular due to Re-Entry Policy. Even when in some countries, the policy is not official, for example Malawi and Tanzania, it is generally accepted as a norm aimed at ensuring the girl child is given a platform to rise to her full potential through the agency of education. Being among the three nations that have a well-established Re-Entry Policy, Zambia has since 1997 adopted workable measures to attain the universal Basic Education for all. This 
came to fruition in 2015 and has continued to be one of the priority areas in the $7^{\text {th }}$ National Development Plan and the Copperbelt Province Strategic Plan (2017-2021), and the vision 2030.

Consistence in the implementation of the Re-Entry Policy by individual schools, which by law are mandated to do, has helped change societal perception on teen pregnancy. Opposed to regarding teen pregnancy as an evil act and the end of the victim's education, teachers and the communities have changed their perception and understanding to seeing it as a social problem. The findings have reviewed that long gone are the days when people looked at a pregnant school girl as a wreck or most condemned member of the community. The Re-Entry Policy is now a sigh of relief and a window of hope to many teen mothers to realize their educational dreams and subsequently join the labor market. Moreover, no community is immune to teen pregnancy. This reaffirms Testa's study in the United States of America, a vindication that the problem is global in nature. It is against this background that advocates of the Re-Entry Policy campaigned against the expulsion of pregnant school girls. It is thus worth saying that teen pregnancy has evolved into a serious social problem equal to poverty, hunger and HIV/AIDS.

In the pre-1997 Zambia, teen pregnancy meant the end of the girl's academic dream. Hundreds of girls met their academic fate through teen pregnancy. The rationale against this thought was that, the girl child was sent into the community ill prepared for challenges that came with realities of life. The perceived low quality of life for women and girl children was therefore deemed as a creation of society and not a matter of ability. The harsh laws acted as a great obstacle to girl child education and feminism.

Both the findings and the literature review are alive to the fact that there is no connection between teenage pregnancy and failing to get a good grade in mathematics. What connects the activating event (Teen Pregnancy) and a consequence (Poor grade in mathematics) is the distortion in the belief system. The belief system has been developed through interaction with society. It is a creation of society. Rigid religious, social and political practices feeding the mind of the child makes it irrational and distorted such that she begins to associate teenage pregnancy to poor results in mathematics. In this way, many teen mothers have ended up getting poor grades in the subject.

The varying views of respondents are agreeable to the fact that, the connection between the Re-Entry Policy and poor results in mathematics is caused by unclear policy guidelines on how to execute it and its ineffective implementation. If the above concerns are addressed, the perception is that reentered girls' performance in mathematics would greatly improve. The dropout rate for teen mothers would equally reduce below imaginable levels.

It is also imperative to understand that the continued poor results in mathematics defeat the very essence the policy was launched. The Re-Entry Policy was launched with a view to reduce gender discrepancies in education and the world of work. Mathematics is a criterion of purity for selection to tertiary education and well-paying jobs. As such, graduating the reentered girl child with a very poor grade in mathematics is tantamount to profitless folly.

However, the general perception as evidenced by this research is that, the results for reentered girls in mathematics are poor thereby defeating the essence of the policy. A poor grade in mathematics lures their prospects for a better and reputable employment. In a way, the policy has not successfully dealt with tenets of gender stereotype society has since time immemorial been fighting to eradicate. The views given by different stakeholders therefore, simply shows us that the policy is now turning to be one a cause for reentered girls' poor performance in mathematics.

\subsection{Challenges Faced by Reentered Girls and How They Affect Their Performance in Mathematics}

Stigma, lack of parental support for reentered teen mothers and a low self-esteem in reentered teen mothers came out in the findings, reaffirmed by the literature review as the major challenges faced by reentered girls affecting their performance in mathematics.

Teen mothers come from within the community and our understanding in this respect is that teenage pregnancy is a creation of society. It is a social construct. Teenage pregnancy did not exist in the pre-historic and colonial era, partly even in the First Republic. Due to cultural lag, in some communities, it is considered to be a form of European Cultural Imperialism. Among African communities, a girl who becomes of age is ready for marriage (teenager).

It was not until the call for Female Education that social activists gave a label "Teen Pregnancy" to those who became pregnant in the ages between twelve and twenty. The legal institutions then criminalized it, social actors and activists campaigning against it such that society began looking at one who becomes pregnant in the teen age as a social misfit. Pre1997 educational policies and how they were implemented on those found wanting led to the development of a society inculcated in norms that demonized teen mothers. The Zambian society thus developed negative attitude, perception and discrimination to the teen mothers.

However, despite the declaration of girl friendly policies such as the "Re-Entry Policy", stigma is still taking a center stage in the communities against teen mothers, especially those still in their primary and secondary school years. International statutes and conferences have just lessened the 'stigma' and not completely wiping it out because it is something that has evolved and inclined in the Zambian society throughout history. Based on this understanding, it is worth saying that pregnant school girls are not immune to stigma on grounds that the Re-Entry Policy is in effect.

The people who are entrusted with the responsibility to ensuring the school environment is safe for reentered girls instead do the exact opposite. They take a leading role in labeling and stigmatizing the victims making the environment hostile for them. Policy makers are nonexceptional in this regard. For example, in the neighboring 
Tanzania, President Magufuli abolished and demonized the Re-Entry Policy. This and many other challenges are enough evidence that the mainstream education system is not conducive for teen mothers largely due to stigma, hence, justifying the reason why they lack concentration and subsequently reap poor results in key subjects like mathematics.

The home environment and society are equally hostile and fertile for stigmatization because of religious and cultural norms/values. Religion is seen to be one of the main sources of stigmatization for re-entered girls. The Christian religion for example, preaches against sex before marriage and those doing so are said to sin against God. Pregnant school girls are therefore tagged as such. The same can be said for Islam, whose ultimate punishment is stoning to death. Religious teachings and practices therefore give no room for acceptance of the Re-Entry Policy. Devote converts of these religious faiths and traditions mistreat the re-entered girls. In turn, the re-entered girls are emotionally affected, a thing that lowers the concentration levels in academic work. In this way, we ardently justify how stigma due to religion adversely affect re-entered girls' performance in mathematics.

As evidenced by this research, stigma causes emotional and psychological pain on the victim. For teen mothers, it is a recipe for humiliation and a creation of a restrictive environment detrimental to sound academic pursuit not only in mathematics but in other academic disciplines as well.

Parents usually have high hopes and dreams for their children. Their wish is to get the most out of them. The socio-cultural, economical and religious inclinations make it very difficult for parents to accept that their child is a victim of teen pregnancy. It is for this reason why parents react differently to news pertaining their child becoming a victim of teen pregnancy. Unless they are counselled, most of them either send their daughter out of their home, to other relatives or simply vow never to lender any support. All these acts by parents and most importantly withdrawing their support create a life of doom in the child. A feeling of rejection and the psychological pressure the child is subjected to makes her to lose hope. Self-pit, especially in instances when the man responsible of the pregnancy also seem not to care yields low self-esteem, a precursor for poor results in mathematics.

Having been rejected by both the parents and the man responsible for the pregnancy, most girls resort to salvage every kind of work that comes their way with a view to raise a bit of income in preparation for the baby. The trends continue even after delivery. As the saying goes: "You cannot serve two masters at once", academic work is usually the one that suffers. As such, the physiological, safety and love needs takes precedence to esteem needs.

Worse still, victims of teenage pregnancies mostly come from low-income families [14]. This was equally justified by the findings of this research, in which the prevalence rate was relatively high for school 1 and 3 respectively. These schools serve communities that are flooded with low-income families. It should also be borne in mind that such parents are largely to blame for their child becoming pregnant. This further explains why the retention levels for teenage mothers at schools 1 and 3 are very low compared to school 2, which is located in the Central Business District (CBD).

Failing mathematics becomes a red tape for progression to tertiary level. Teen mothers languish in the townships with their poor results. The vicious cycle of poverty catches up with them. Their children too risk going through the same or similar process. In the end, males who even after making them pregnant are let scotch free remain dominant in the world of work. If looked at it from this perspective, lack of socio-economical support to the girl child is both a cause and a consequence of teenage pregnancy as well as poor performance in mathematics. As if this is not enough, the ReEntry Policy in its current form only give school management powers to award a maternity leave. While the child is seen to enjoy the rights of staying home until she gives birth and be readmitted into the mainstream school thereafter, there is absolutely no room for redemption in the academic realms.

The Re-Entry Policy implemented in secondary schools lacks merit in terms of ensuring re-entered girls attain a high self-esteem. School Guidance and Counseling Teachers do not make serious and concrete programs to help the victims with copying behaviors in their newly acquired socio status.

Teen mothers look at themselves as a shame to the community, family, church and friends. They are confused on how to address themselves, that is, as being either adults or children. The fact however is that, they are children and need to be treated as such.

Low self-esteem may bring about inferiority complex in them. Acting out of self-defense, they are prone to make more errors and eventually lose their peers in the process. They cannot contribute in class or get actively involved in all school activities. When faced with a mathematical problem, the only person they approach is the teacher if possible. Peers on the other hand distance themselves from them. The fact that no man is an Island, their new status pushes them between the rock and the hard place. By no doubt, this leads to timidity and eventually poor results. This among other reasons is a leading cause for poor results in mathematics.

\subsection{Implementation of the Re-Entry Policy in Mufulira District}

The Re-Entry Policy is law. All schools in Zambia are expected to implement it without any reservations. Alive to this fact, all public schools, primary and secondary schools alike implement the policy. However, there seem to be individual variations on how the policy is being implemented. This is reflected in the results presented in the findings.

Schools in the Central Business District have less Re-Entry cases and high retention levels for re-entered mothers compared to those located in the peripherals of the district.

Generally, the performance of the reentered girls is not impressive and is the reason why Tanzanian President, Magufuli was on point when he said the Re-Entry Policy cause lawlessness in schools and poor results for girls, 
including those who are pregnant free. Moreover, a child needs to be indoctrinated. If left to move for a mile, they move a thousand more miles away from your care. Strict rules are needed to make children strive for excellence and avoid vices that would lead them into having poor results due to divided attention.

\section{Conclusion and Recommendations}

\subsection{Conclusion}

It is the wish of every Government to develop a sound education system. Moreover, education is human capital investment. It gives the nation, the much-needed work force to drive the economic wheels of a country. It is for this apparent reason that the Zambian Government has joined the rest of the world to democratize its education system by making it more inclusive, with no one left behind. One such policy, which has since 1997 been so instrumental in realizing this dream, is "The Re-Entry Policy." However, much need to be done on its implementation.

Because of poor implementation of the policy, it has evolved to become a major cause of poor performance in key subjects like mathematics. As such, it has not addressed a number of concerns it lays its foundation upon, for example, reducing gender discrepancies in mathematics and mathematics related courses/employment. It still lacks merit on the implementation and curbing the numerous challenges reentered girls are faced with in schools.

Social activists, the Government and NonGovernmental Organizations however, are still optimistic that the situation as regards to reentered girls' poor performance in key subjects like mathematics and science will improve over time. All that is needed is to find lasting solutions to challenges discussed in this paper.

Unless, sustainable measures are put in place, quality results in mathematics for reentered girls will remain a pipe dream.

\subsection{Recommendations}

The conclusion made upon analyzing the findings is that teenage pregnancy is unavoidable and a growing social problem. Abolishing the policy as was the case with Tanzania is not a solution. The problem is not in the policy but how it is being implemented. In view of this, the following recommendations based on the research findings have been suggested if stakeholders are poised to ensuring reentered girls' performance in mathematics improves:

1. The Ministry of General Education through schools should carry out mass sensitization campaigns to educate communities on the Re-Entry Policy.

2. Involve re-entered girls in all school activities to make them develop a positive self-image so as to lessen stigmatization
3. Teachers' pedagogy and language should be censored and encouraging to reentered teen mothers.

4. Reduce all forms of discrimination and abuse to reentered girls.

5. Strengthening the school-community relationship through the PTA meetings to acquaint them with new developments and policies such as the Re-Entry Policy.

6. Parents, who have abandoned their child because of the shame that comes with teenage pregnancy, should be counselled and encouraged to continue supporting the victim by the school administrators and school counsellors.

7. The Ministry of General Education through PTA, School Boards and School Administration to find means of raising funds to employ nannies or baby sitters to take care of the babies for teen mothers. The intent is to increase their attendance and concentration at academic work.

8. Government and Non-Governmental organizations should fund schools to help them successfully implement the Re-Entry Policy.

\section{References}

[1] D. C. Dollahite, L. D. Marks, and H. Dalton, "Why Religion Helps and Harms Families: A Conceptual Model of a System of Dualities at the Nexus of Faith and Family Life: Why Religion Helps and Harms Families," J. Fam. Theory Rev., vol. 10, no. 1, pp. 219-241, Mar. 2018.

[2] S. Kirchengast, "Teenage Pregnancies: A Worldwide Social and Medical Problem," in An Analysis of Contemporary Social Welfare Issues, R. Laratta, Ed. InTech, 2016.

[3] F. Bahçeci and M. Gürol, "The Effect of Individualized Instruction System on the Academic Achievement Scores of Students," Educ. Res. Int., vol. 2016, pp. 1-9, 2016.

[4] S. Hesse-Biber, "Qualitative Approaches to Mixed Methods Practice," Qual. Inq., vol. 16, no. 6, pp. 455-468, Jul. 2010.

[5] P. M. Podsakoff, S. B. MacKenzie, J.-Y. Lee, and N. P. Podsakoff, "Common method biases in behavioral research: A critical review of the literature and recommended remedies." J. Appl. Psychol., vol. 88, no. 5, pp. 879-903, 2003.

[6] I. I. Munene, "PROVIDING BASIC EDUCATION FOR ALL IN AFRICA: WHAT WE HAVE LEARNED," Afr. Educ. Rev., vol. 12, no. 1, pp. 1-6, Jan. 2015.

[7] S. E. Johns, T. E. Dickins, and H. T. Clegg, "Teenage pregnancy and motherhood: How might evolutionary theory inform policy?," J. Evol. Psychol., vol. 9, no. 1, pp. 3-19, Mar. 2011.

[8] A. Ayalew and K. Abreha, "Magnitude and Predictors of Early Sexual Debut among High and Preparatory School Students in Northern Ethiopia: A School-based Crosssectional Study," J. Health Educ. Res. Dev., vol. 03, no. 03, 2015.

[9] C. Gyan, "The Effects of Teenage Pregnancy on the Educational Attainment of Girls at Chorkor, a Suburb of Accra," J. Educ. Soc. Res., Sep. 2013. 
[10] T. Leone, "Measuring Differential Maternal Mortality Using Census Data in Developing Countries: Maternal Mortality Census," Popul. Space Place, vol. 20, no. 7, pp. 581-591, Oct. 2014.

[11] UNDP, Human Development Report 2015. United Nations Development Programme, 2016.

[12] J. Cuesta, P. Kabaso, and P. Suarez-Becerra, How Pro-Poor and Progressive is Social Spending in Zambia? The World Bank, 2012

[13] I. Yakubu and W. J. Salisu, "Determinants of adolescent pregnancy in sub-Saharan Africa: a systematic review," Reprod. Health, vol. 15, no. 1, p. 15, Dec. 2018.

[14] L. Dean et al., "'He is suitable for her, of course he is our relative': a qualitative exploration of the drivers and implications of child marriage in Gezira State, Sudan," BMJ Glob. Health, vol. 4, no. 3, p. e001264, May 2019.

[15] World Bank, World Development Report 2019: The Changing Nature of Work. The World Bank, 2018.

[16] S. Duncan, "What's the problem with teenage parents? And what's the problem with policy?," Crit. Soc. Policy, vol. 27, no. 3, pp. 307-334, Aug. 2007.

[17] G. O. Eigbiremolen, "Determinants of Learning among Primary School Children in Ethiopia: Analysis of Round 2 and 3 of Young Lives Data: Determinants of Learning in Ethiopia," Afr. Dev. Rev., vol. 29, no. 2, pp. 237-248, Jun. 2017.

[18] N. A. A. Opoku-Asare and A. O. Siaw, "Rural-Urban Disparity in Students' Academic Performance in Visual Arts Education: Evidence From Six Senior High Schools in Kumasi, Ghana," SAGE Open, vol. 5, no. 4, p. 215824401561252 , Dec. 2015.
[19] M. Aakhus and E. Rumsey, "Crafting Supportive Communication Online: A Communication Design Analysis of Conflict in an Online Support Group," J. Appl. Commun. Res., vol. 38, no. 1, pp. 65-84, Feb. 2010.

[20] G. Ramirez, S. Y. Hooper, N. B. Kersting, R. Ferguson, and D. Yeager, "Teacher Math Anxiety Relates to Adolescent Students' Math Achievement," AERA Open, vol. 4, no. 1, p. 233285841875605 , Jan. 2018.

[21] J. M. Katamei and G. A. Omwono, "Intervention Strategies to Improve Students' Academic Performance in Public Secondary Schools in Arid and Semi-Arid Lands in Kenya," Int. J. Soc. Sci. Stud., vol. 3, no. 4, pp. 106-119, Jun. 2015.

[22] C. Sable et al., "Best Practices in Managing Transition to Adulthood for Adolescents With Congenital Heart Disease: The Transition Process and Medical and Psychosocial Issues: A Scientific Statement From the American Heart Association," Circulation, vol. 123, no. 13, pp. 1454-1485, Apr. 2011.

[23] C. O'Brien Cherry, N. Chumbler, J. Bute, and A. Huff, "Building a 'Better Life': The Transformative Effects of Adolescent Pregnancy and Parenting," SAGE Open, vol. 5, no. 1, p. 215824401557163 , Mar. 2015.

[24] OECD, Ed., Equity and quality in education: supporting disadvantaged students and schools. Paris: OECD publishing, 2012.

[25] P. L. East, "The First Teenage Pregnancy in the Family: Does It Affect Mothers' Parenting, Attitudes, or Mother-Adolescent Communication?" J. Marriage Fam., vol. 61, no. 2, p. 306, May 1999. 